\title{
Disaster Management Plan for Girnar Ropeway as per Environmental Setting at Mount Girnar
}

\author{
Arjun Bhindora, Dhruv Pansheriya
}

\begin{abstract}
Over the last two decades, there is growing interest from many companies on disaster management and practices. Organizations want to lead to sustainable workforces and embrace the high performance of the service organization. The topic is of great significance in particular in the context of tourist attraction in Junagadh. The project site stretches from the foot of Mount Girnar to a point near the Ambaji Temple at the top of the Mountain. Land required for this project is $72,817 \mathrm{~m} 2$. The project will be developed as a mode of transportation for carrying pilgrims from the foot of Mount Girnar to Ambaji Temple This paper reviews the expectation of disaster balance as per the environmental impact such as the festival of "Maha Shivratri" also considering the tourist attraction and provides a suitable context for them.A qualitative approach in a single case study identified various elements of environmental disaster balance initiatives, related outcomes in their performance. The EMP provides a delivery mechanism to address potential adverse impacts and to introduce standards of good practice to be adopted for all project works. For each stage of the programme, the EMP lists all the requirements to ensure effective mitigation of every potential biophysical and socio-economic impact identified in the EIA. Aerial Ropeway Transportation technologies (ART), a type 13 of aerial transportation mode in which passengers are transported in cabins that are suspended 14 and pulled by cables, is one popular example of these technologies. The recent introduction of 15 this technology into the urban environment, in addition to the vendors' continuous trials to 16 improve upon existing aerial ropeway technologies has led to several recent advancements and 17 improvements to the technology as illustrated by several recent implementations around the 18 world. In this article, we try to shed some light on some of the most recent improvements in the 19 technology specifications, operation and safety considerations of ART technologies as observed 20 from several case studies around the world.
\end{abstract}

Index Terms - Air monitoring, Climate of the study area, Environmental monitoring plan, Population of the study area, Traffic survey.

\section{INTRODUCTION}

The aerial ropeway project named 'Udankhatola' will be developed at Mount Girnar in Junagadh District, State Gujarat. The project site stretches from the foot of Mount Girnar to a point near the Ambaji Temple at the top of the Mountain. Land required for this project is $72,817 \mathrm{~m} 2$. The project will be developed as a mode of transportation for carrying pilgrims from the foot of Mount Girnar to Ambaji

Arjun Bhindora, Final Year Student, Department Of Applied Mechanics, Sardar Vallabhbhai National Institute Of Technology, Surat, Gujarat.

Dhruv Pansheriya, Final Year Student, Department Of Applied Mechanics, Sardar Vallabhbhai National Institute Of Technology, Surat, Gujarat.
Temple. Though a large number of pilgrims and tourist visit the hill temple braving all the adversities, many are held back due to the hill's inaccessibility and arduous climbing of over 10,000 steps

The Girnar passenger ropeway will link the foothills to the top of the mountain near Ambaji temple and will quickly and comfortably transport the pilgrims to the hilltop. The 2300 meter long ropeway with a lift of about 850 meters will have a carrying capacity of 1000 passenger per hour and will carry pilgrims to the hilltop in about 9.28 minutes against step climbing of 5 hours. Ropeway being highly environment-friendly causing almost no noise, water or air pollution is the most efficient and economical mode of transport in this hilly terrain where other means of transport do not exist.

The total plot area is $72,871 \mathrm{~m} 2$

- Lower Station Area is 21,917 m2

- Line Area (trestles, electrical lines, water lines etc.) is $36,845 \mathrm{~m} 2$

- Upper Station Area is 8,000 m2

- Area for staff accommodation \& amenities is $6,109 \mathrm{~m} 2$

\section{Length of Alignment}

- The inclined length between two stations: 2,382.49 m

- The horizontal length between two stations: $2,171.40 \mathrm{~m}$ Vertical rise: $850 \mathrm{~m}$

\section{Features of the Aerial ropeway}

- Monocable Detachable Grip type system

- The capacity of carrying: 1,000 passengers per hour

- Line speed: $5 \mathrm{~m} / \mathrm{s}$ (maximum)

- Cabin capacity: 8 passengers

- Travel time: $9.28 \mathrm{~min}$

- Length of forest land crossing: $1,750 \mathrm{~m}$

\section{ENVIRONMENTAL SETTING}

\subsection{Rainfall}

The total rainfall in a year is observed to be $834.9 \mathrm{~mm}$. Distribution of rainfall by season is $1.5 \mathrm{~mm}$ in winter (December, January, February), $43.9 \mathrm{~mm}$ in summer (March, April, May), $203.83 \mathrm{~mm}$ in monsoons (June, July, August, September) and $21.5 \mathrm{~mm}$ in post-monsoon (October November).

\subsection{Cloud Cover}

The area remains cloudy between July - September, which is the active period of the monsoon season. Generally cloud cover ranges from 3.7 to 6.3 Oktas during this monsoon season. 


\subsection{Humidity}

Most humid conditions are found in the monsoons, followed by post-monsoon, summers and winter in that order. Mornings are more humid than evenings and humidity ranges from a high of $85-88 \%$ in monsoon mornings to a low of $23-26 \%$ in winter evenings. During the post-monsoon season, humidity remains between $52-72 \%$ in the morning and between $29-41 \%$ in the evening. Nearest IMD station from the project site is Keshod Aerodrome, Keshod.

\subsection{Site Specific Meteorology}

Site-specific meteorological data for the summer season has been collected from the site. The parameters for which data has been collected are:

- Wind Speed

- Wind direction

- Temperature

- Relative Humidity

- Cloud Cover

\subsection{Geological Features and Seismic Zones \\ Geology}

About two third of the district is covered under a thick pile of Deccan Trap after forming linear plateau \& conical ridges. The major rock types are basalt, rhyolite, granophyre, microgranite, porphyry, gabbro, monzonite etc.

These rock types have been extensively intruded by both basic \& acidic dykes. Laterite caps occur at the top of Deccan traps. Tertiary sediments of Gaj, Dwarka, Miliolite \& ChayaFormations occur along the coastal belt. These sediments of lower Miocene to Pleistocene age mainly consists of miliolite, limestone, Variegated Clays, Marl \& polymict conglomerate. The miliolite \& Gaj limestones form huge reserves of chemicals and cement grade limestone. The quaternary sediments of Holocene age mainly consist of tidal flat, flood plains, channel fill and coastal sand dune deposits and have been grouped under Rann clay Formation, Malva Formations, Katpur Formations, Varahi Formation and Akhaj Formation. The soil is mainly loamy calcareous \& well drained. The district has a large area covered under basic magnetism. A hot water spring with a temperature of 500C is located near

Tulsishyam. Bouger gravity anomly has a great variation from -10 to $+60 \mathrm{~m}$ Gal. the depth of basement is $1500 \mathrm{~m}$ in North and decrease to South. The Southwest coast of the district is defined by a very prominent fault.

The groundwater prospects are not very good because of basaltic terrain. However in miliolite limestone, along with the coastal belt, depth of ground water is only $5 \mathrm{~m}$. Mineral Resources Junagadh district is well endowed with limestone, bauxite and salt resources base metals $(\mathrm{Pb} \& \mathrm{Cu})$ occurrences are found in Banej. Bauxite occurs in laterite caps near Deorana \& South of Maliya-Hatina. Bentonite bands are found near Char, Miyani and South of Maliya Hatina. Chalk is mined extensively at Adityana. Ranavav \& Modmala clay pockets are extensively found at Sheriyakhan, Deorana \& Porbandar, East of Ranavav, Balej \& around Wadia. About 120 million tones of limestone resources in Gaj Formation have been estimated around Sheriyakhabn, Deorana \& Pharer. A sizable amount of the Gaj limestone is of the chemical grade. Salt is obtained from seawater at Kuchhkadi \& Miyani. Source: Geological Survey of India, Junagadh District Seismicity The entire district is covered under moderate zone (Zone III) of Seismicity (Map III), which is classified as having a fairly high probability of earthquake shocks measuring 5-6 on the Richter scale, low probability of shocks of 6-7 on the Richter scale, and even occasional the occurrence of shocks of 7-8 on the Richter scale cannot be ruled out.

Source: GSHAP Hazard Map.

\section{SAFETY ASSEMBLY (SCHEMATIC)}

\section{ROPE}

The rope will be of Stranded construction with a synthetic core. This will support, as well as, haul the cabins.

Rope construction is 6 X 19 Seale with PP core.

Splicing: - It is the process, of joining the two ends of the rope, to make a continuous loop. This is carried by a specialized team from rope manufacturer. Proposed ropeway will have one spliced joint for the ropes.

\section{PLANT SAFETY DEVICES}

An adequate number of safety devices are provided in ropeway to monitor all critical assembly for their normal functioning.

In case of any technical abnormality, the safety features will stop the ropeway.

\section{SAFETY FEATURES}

Service Brake:

The disc brake is mounted on the coupling and is located between the gearbox and the electromotor. It acts when:

o electric motor stops

o electric motor over speeds by $10 \%$

o a safety function is applied

o a service stop button is pushed

\section{Emergency Brake}

A spring-applied calliper - brake acts directly to the drive wheel. The emergency brake is lifted hydraulically and stays open. The braking torque and the lifting gap is variable and can be adjusted separately. The brake shoe is controlled with a safety switch. The E-brake operates automatically when: o One of the emergency stop buttons is (activated) o If the pressure is lost in the hydraulic brake-cylinder o If speed has surpassed $15 \%$ max. design speed

\section{Rope Derailment Detection:}

Two break fork switches are installed on each sheave assembly, one on the in- and one on the outgoing side. The switch will be activated through the dropping of the heavy sheave and will break the fork. This will stop the ropeway if the rope should derail. This function will also assure the breaking of the fork should the rope not land in the rope catcher. 


\section{Door Closing Control Device:}

Prior the cabin is leaving the station; the closing of the door will be checked by two independent checking procedures. In case the system detects on the open door, the ropeway stops immediately.

The doors position is checked:

o By a limit switch at the door mechanism.

o By a sensor, if the closing force to door mechanism is too high.

\section{Emergency button:}

In case a dangerous situation is observed, an emergency button can be pressed and brings the ropeway immediately to a stop. The emergency button is conspicuously marked in red and yellow colour. In total are three such buttons installed:

o Passenger area at the bottom station

o Passenger area at the top station

o Control room

o Cableway drive

Normal stoppage button:

Normal stop buttons are provided to stop ropeway normally.

Wind speed indicators:

Wind speed indicators are installed on towers and station buildings to continuously monitor the wind speed and take precautionary measures accordingly.

Lightning protection:

The advance lightning protection system is installed to avoid any damage due to lightning considering the full coverage of ropeway areas.

Guides at entry \& exit of the station:

Guides are provided at entry \& exit of stations to restrict cabin movement and ease of boarding \& de-boarding for passengers.

Electrical protection:

Various safety features provided in the electrical system are listed below.

o Speed regulation

o Over Speed

o Under / Over Voltage protection

o Overload / Overcurrent

o Tension System interlock with system safety

o Cabin swing at the tower

o Cabin entry sensing automatically

o Hydraulic pump healthiness

o Rope earthing

o Lightning Protection

o OverWind Speed

o Regenerative power control

o Phase sequence monitoring

o Transformer temperature monitoring

o Motor temperature monitoring

Fault logging is carried out in the drive.

\section{RESCUE AND EMERGENCY}

Full capacity Diesel generator

In normal condition, ropeway is run with SEB power. However, a full capacity diesel generator is installed in the ropeway unit to run ropeway at full capacity in case of power failure.

\section{Evacuation Drive}

In case of a malfunction or a power loss of the main drive, passengers can easily be evacuated without leaving the cabin by a diesel-hydrostatic drive and hydraulic motor drive.

\section{Location}

The diesel-hydrostatic \& hydraulic motor evacuation drive is located on the steel frame at the drive-/tension station. Its location enables the operation of the emergency drive and braking system by one person.

Procedure of Use

Failure of electric power and main drive

o Joining the emergency drive to the ring gear at the drive bull-wheel.

o Removing the coupling chain of the bull-wheel.

o Operating the emergency drive in coordination with the braking system

\section{Environmental Conditions}

Particular the entire bottom-line of under the ropeway shall be free and cleared from obstacles. This is required for an easy access of rescue-crew and rescued passenger movement. Requisite measures are taken for the stability of terrain against any natural constraints.

Manual rescue:

Manual rescue is carried in case it is not possible to run the ropeway installation with the help of skilled and trained manpower. Detailed guidelines are laid down for the instruction of carrying manual rescue. Monthly rescue drills are carried out to ensure the effectiveness of rescue systems.

Equipment

Equipment for rescuer "on the hauling rope", consisting of: o Aluminium safety hook and screw-link (Rescue carriage)

o Rescuer chair

o Full body harness (Safety belt)

o Helmet

o Gloves

Lowering equipment for a passenger to be evacuated consisting of:

o rope deflection device with aluminium safety hook and screw link

o Material bag (storage of rope)

o Special rope

o Rescue chair with harness (where the passenger is sitting)

Equipment for the rescuer "on the ground "consists of:

o Rope brake with a carbine 
o Gloves

o Helmet

o Water bottle

o First aid items

o Evacuation:

o Principle

1. Rescue person climbs the tower,

2. moves with special rescue device to the gondola,

3. lowers himself to the door level of the gondola,

4. position and secure himself and instructs passengers of rescue procedure,

5. opens the door,

6. pulls the rescue chair to the passenger,

7. stay at the cabin and help in lowering passenger to the ground, boat etc.,

8. another rescue person on ground receives passenger and takes rescue device from him

9. rescue person at ground pulls the chair back to the gondola, 10. procedure step 6 to 9 will be repeated until gondola is empty,

11. procedure step 2 to 10 will be repeated until all cabins are evacuated.

\section{ENVIRONMENTAL MANAGEMENT PLAN}

\subsection{General}

We have identified a number of impacts that are likely to arise. Where adverse impacts have been identified, the EIA has examined the extent to which these impacts would be mitigated through the adoption of standard practice and guidelines and following legislative requirements of the Gujarat Pollution Control Board (GPCB). The Environmental Management Plan (EMP) describes both generic good practice measures and site-specific measures, the implementation of which is aimed at mitigating the potential impacts associated with the

proposed activities.

4.2 Purpose of the Environmental Management Plan

The environment management plan is prepared with a view to facilitating effective environmental management of the project, in general, and implementation of the mitigation measures in particular. The EMP provides a delivery mechanism to address potential adverse impacts and to introduce standards of good practice to be adopted for all project works. For each stage of the programme, the EMP lists all the requirements to ensure effective mitigation of every potential biophysical and socio-economic impact identified in the EIA. For each impact or operation, which could otherwise give rise to impact, the following information is presented:

- A comprehensive listing of the mitigation measures (actions) that shall implement;

- The parameters that shall be monitored to ensure effective implementation of the action;

- The timing for implementation of the action to ensure that the objectives of mitigation are fully met.

\section{REFERENCE}

[1]Collecter office, tourism development plan

[2] Aapdu Junagadh central office.

[3] Kaarmabhoomi consultancy.

[4] Usha Brecho lim.

Arjun Bhindora, Final Year Student, Department Of Applied Mechanics, Sardar Vallabhbhai National Institute Of Technology, Surat, Gujarat.

Dhruv Pansheriya, Final Year Student, Department Of Applied Mechanics, Sardar Vallabhbhai National Institute Of Technology, Surat, Gujarat.. 